\title{
The effects of acute ischemia on the isovolumic index
}

\begin{abstract}
The isovolumic index is the ratio of the duration of isovolumic contraction (IVC) and relaxation (IVR) divided by ejection time (ET), and has been proposed as a more sensitive descriptor of ventricular performance than the systolic time index, which ignores the period of isovolumic relaxation. To determine the effects of acute ischemia on these indices, IVC, IVR, and ET were measured in seven open-chest dogs instrumented with high-fidelity micromanometers and ultrasonic crystals and subjected to a 10-second period of coronary occlusion. Fractional shortening was significantly impaired $(18.4 \pm 6.9 \%$ vs $1.9 \pm 7.3 \%, p<0.001)$ during coronary occlusion. ET was unaffected by the brief ischemia, whereas IVC time showed directional shortening that attained statistical significance $(55 \pm 7$ msec control vs $50 \pm 6 \mathrm{msec}, p<0.01)$ at 8 to 10 seconds. IVR time was prolonged by occlusion, significantly so at 6 to 8 seconds (72 $\pm 26 \mathrm{msec}$ control vs $88 \pm 22 \mathrm{msec}, p<0.01$ ) and at 8 to 10 seconds $(81 \pm 19 \mathrm{msec}$, $p<0.05)$. The systolic time index showed no deterioration during ischemia, whereas the isovolumic index did show directional prolongation. Assessment of IVC, IVR, and ET at the time of the maximal change in the isovolumic index revealed significant changes of IVC and IVR (each $p<0.05$ vs control), though ET and the systolic time index were unchanged. Through incorporation of IVR, the isovolumic index was more sensitive to acute brief ischemia than the systolic time index. (AM HEART J 1988;115:978.)
\end{abstract}

Mark J. McGillem, B.S., Scott F. DeBoe, B.S., and G. B. John Mancini, M.D., F.R.C.P.(C). Ann Arbor, Mich.

The isovolumic index, defined as the sum of the total time of isovolumic contraction and relaxation divided by ejection time, was formulated to take into account abnormalities of relaxation known to occur in patients with left ventricular myocardial disease. ${ }^{1-9}$ The isovolumic index has been demonstrated to be a sensitive measure of left ventricular dysfunction in patients with cardiomyopathy and coronary artery disease ${ }^{10}$ Recent animal studies ${ }^{10-12}$ have compared it to the traditional systolic time index, and have quantified its hemodynamic determinants and its response to various cardioactive drugs. The purpose of this investigation was to examine, in a canine model, the effect of a period of brief coronary occlusion on the systolic and diastolic time parameters involved in calculation of both the isovolumic index and the systolic time index.

From the Department of Internal Medicine, Division of Cardiology, Veterans Administration Medical Center, University of Michigan Medical School.

This study was supported in part by funds from the Veterans Administration, Washington, D.C., and from The American Heart. Association of Michigan, Lathrup Village, Mich.

Received for publication July 16, 1987; accepted Jan. 4, 1988.

Reprint requests: G. B. John Mancini, M.D., Veterans Administration Medical Center (111A), 2215 Fuller Rd., Ann Arbor, MI 48105.

\section{METHODS}

Seven mongrel dogs of either sex (mean weight $25 \pm 3.6$ $\mathrm{kg})$ were anesthetized with sodium pentobarbitol (35 $\mathrm{mg} / \mathrm{kg})$, intubated, and ventilated $(15 \mathrm{ml} / \mathrm{kg})$ with a Harvard respirator. A left carotid arteriotomy and jugular venotomy were performed and sheaths were inserted for vascular access. A left thoracotomy was performed in the fifth intercostal space and the heart was suspended in a pericardial cradle. High-fidelity micromanometers (No. $5 F$, Millar Instruments Inc., Houston, Texas) were inserted via the left carotid sheath into the ascending aorta, via a left ventricular apical stab wound into the left ventricle, and via a left atriotomy into the left atrium and then advanced through the mitral valve into the left ventricle. The catheters were made equisensitive by matching the systolic blood pressure readings of the left ventricular and aortic manometers and by matching the high-gain left ventricular diastolic pressures of the left atrial and left ventricular catheters. Once this was achieved, the left atrial catheter was withdrawn through the mitral valve into the left atrium. Frequent checks for zero drift were made throughout the experiments.

The left anterior descending artery was dissected free for 2 to $3 \mathrm{~cm}$ and was surrounded with an appropriately sized and calibrated electromagnetic flow probe and an elastic vessel loop. The vessel loop was used to occlude the artery for a 10-second period, and measurements of coronary flow were used to determine when postocclusion, steady-state conditions were reattained. 
Table I. The effects of acute ischemia on hemodynamics, regional function, and time intervals

\begin{tabular}{|c|c|c|c|c|c|c|}
\hline & \multirow[b]{2}{*}{ Control } & \multicolumn{4}{|c|}{ Duration of ischemia (sec) } & \multirow[b]{2}{*}{ Recovery } \\
\hline & & $2-4$ & $4-6$ & $6-8$ & $x .70$ & \\
\hline Heart rate (beats/min) & $155 \pm 22$ & $154 \pm 19$ & $155 \div 19$ & $156 \pm 20$ & $157 \pm 20$ & $151 \pm 16$ \\
\hline $\begin{array}{l}\text { Left ventricular end-diastolic } \\
\text { pressure }(\mathrm{mm} \mathrm{Hg})\end{array}$ & $10 \pm 5$ & $11 \pm 6$ & $12=7$ & $13 \pm 7+$ & $13 \pm 7+$ & $10 \pm 5$ \\
\hline $\begin{array}{l}\text { Systolic blood pressure (mm } \\
\mathrm{Hg} \text { ) }\end{array}$ & $130 \pm 15$ & $129 \pm 15$ & $128 \pm 15$ & $128 \pm 16$ & $129 \pm 17$ & $132 \pm 14$ \\
\hline $\begin{array}{l}\text { Peak positive } \mathrm{dP} / \mathrm{dt}(\mathrm{mm} \\
\mathrm{Hg} / \mathrm{sec})\end{array}$ & $2044 \pm 695$ & $1973 \pm 620$ & $1940 \pm 612$ & $1941 \pm 629$ & $1971 \pm 662$ & $2073 \pm 683$ \\
\hline $\begin{array}{l}\text { Peak negative } \mathrm{dP} / \mathrm{dt}(\mathrm{mm} \\
\mathrm{Hg} / \mathrm{sec} \text { ) }\end{array}$ & $2155 \pm 556$ & $2005 \pm 505$ & $1730-498+$ & $1595+414 \dagger$ & $1548+.381$ & $2088+482$ \\
\hline $\begin{array}{l}\text { Isovolumic relaxation } \\
\text { half-time (msec) }\end{array}$ & $25 \pm 7$ & $27 \pm 6$ & $30 \pm 6^{*}$ & $31 \pm 9+$ & $31+3+$ & $26 \pm 8$ \\
\hline Fractional shortening $(r)$ & $18.4 \pm 6.9$ & $10.9 \pm 7.8^{*}$ & $5.6 \pm 7.5 \ddagger$ & $2.8 \pm 7.7 \hbar$ & $1.9+7.8 t$ & $20.9 \pm 7.5$ \\
\hline Ejection time (msec) & $169 \pm 17$ & $170 \pm 19$ & $164 \pm 17$ & $165 \pm 20$ & $167+22$ & $171 \pm 14$ \\
\hline $\begin{array}{l}\text { Isovolumic contraction time } \\
\text { (msec) }\end{array}$ & $55 \pm 7$ & $53 \pm 5$ & $53 \pm 7$ & $52 \pm 7$ & $50 \div 6^{+}$ & $54 \pm 5$ \\
\hline $\begin{array}{l}\text { Isovolumic relaxation time } \\
(\mathrm{msec})\end{array}$ & $72 \pm 26$ & $73 \pm 23$ & $80+24$ & $82 \pm 22+$ & $81+19^{*}$ & $75 \pm 24$ \\
\hline Systolic time index & $0.33 \pm 0.03$ & $0.31 \pm 0.03$ & $0.32 \pm 0.05$ & $0.31 \pm 0.03$ & $0.30 \pm 0.03$ & $0.32 \pm 0.03$ \\
\hline Isovolumic index & $0.75 \pm 0.13$ & $0.74 \pm 0.09$ & $0.80 \pm 0.13$ & $0.81 \pm 0.12$ & $0.78 \pm 0.11$ & $0.75 \pm 0.12$ \\
\hline
\end{tabular}

Values are mean \pm standard deviation.

$\mathrm{dP} / \mathrm{d} t=$ rate of change of pressure with time.

$*=p<0.05 .+=p<0.01, \dagger=p<0.001$, each vs control

A pair of subendocardial ultrasonic crystals were placed in the distribution of the left anterior descending coronary artery in the mid-equatorial plane of the ventricle. The crystal transducers were attached to a sonomicrometer (Model 120, Triton Technology, San Diego, Calif.) interfaced to a wide-band oscilliscope (Model 2213A, Tektronix, Beaverton, Or.) for confirmation of crystal alignment. Subendocardial positioning of the crystals was confirmed by observation of prompt dyskinesis during brief coronary occlusion and by postmortem inspection.

Continuous recordings of left ventricular pressure, first derivative of left ventricular pressure $(\mathrm{dP} / \mathrm{dt})$, aortic and atrial pressures, segment lengths, and ECG were made on a Gould recorder (Model 2800S, Gould Electronics, Cleveland, Ohio). Reported values were averaged from four to six normally conducted beats recorded at $200 \mathrm{~mm} / \mathrm{sec}$ paper speed during control, from two to three beats occurring in five, 2-second periods during the total 10 seconds of coronary occlusion, and from four to six beats at $0.5,1,5$, and 10 minutes postocclusion.

These animals were part of a cohort of dogs that were also studied to determine the effects of intravenous verapamil infusion on the isovolumic index. ${ }^{12}$ The present ischemic intervention was performed prior to cardioactive drug administration.

Data analysis. Measurements of left ventricular enddiastolic pressures were taken at the time when $\mathrm{dP} / \mathrm{dt}$ became positive and this was considered the onset of isovolumic contraction. End systole was taken at peak negative $\mathrm{dP} / \mathrm{dt}$ and this was considered the beginning of isovolumic relaxation. ${ }^{1 ;}$
The isovolumic contraction time was determined as the time from end-diastolic pressure to peak positive $\mathrm{dP} / \mathrm{dt} .^{14}$ The ejection time was determined as the time from peak positive to peak negative $\mathrm{dP} / \mathrm{dt}^{13,{ }^{14}}$ The isovolumic relaxation time was taken from peak negative $\mathrm{dP} / \mathrm{dt}$ to the point where left atrial and left ventricular pressures crossed over. ${ }^{15-19}$

The isovolumic index was defined as [(IVC + IVR )/ $\mathrm{ET})$ ] where IVC = isovolumic contraction time, IVR = isovolumic relaxation time, and ET = left ventricular ejection time. The systolic time index was defined as IVC/ET. Segment shortening was defined as segment excursion between end diastole and end systole divided by enddiastolic length and multiplied by 100 . To determine directional changes in relaxation, an estimate of the isovolumic relaxation half-time was determined by calculating the time required for the left ventricular pressure at peak negative $\mathrm{dP} / \mathrm{dt}$ to decrease by half ${ }^{20.21}$

Data averaged from beats recorded during ischemia were divided into five groups of 2 seconds' duration. There were no significant differences from control in any parameter for the 0 to 2 second observations, and these data are not reported. Likewise, there were no significant differences between any of the four recovery period groups, and only the 30 -second recovery values are reported below.

Statistical analysis. All results are reported as mean \pm one standard deviation, and were analyzed by repeated measures analysis of variance. When overall significance was detected, a Bonferroni test was utilized to determine which stages were significantly different from control. ${ }^{22} \mathrm{~A}$ $p$ value of less than 0.05 was considered significant. 
Table II. Measurements of hemodynamics, regional function, and time intervals at control and at time of maximal isovolumic index value during ischemia

\begin{tabular}{|c|c|c|c|}
\hline & Control & $\begin{array}{l}\text { During maximal } \\
\text { isovolumic index }\end{array}$ & Significance \\
\hline Heart rate (beats/min) & $155 \pm 22$ & $156 \pm 18$ & NS \\
\hline Left ventricular end-diastolic pressure $(\mathrm{mm} \mathrm{Hg} / \mathrm{sec})$ & $10 \pm 5$ & $12 \pm 7$ & $p<0.05$ \\
\hline Systolic blood pressure & $130 \pm 15$ & $130 \pm 17$ & NS \\
\hline Peak positive $\mathrm{dP} / \mathrm{dt}(\mathrm{mm} \mathrm{Hg} / \mathrm{sec})$ & $2044 \pm 695$ & $1954 \pm 646$ & NS \\
\hline Peak negative $\mathrm{dP} / \mathrm{dt}(\mathrm{mm} \mathrm{Hg} / \mathrm{sec})$ & $2155 \pm 557$ & $1577 \pm 447$ & $p<0.05$ \\
\hline Isovolumic relaxation half-time (msec) & $25.1 \pm 7.2$ & $32.4 \pm 4.5$ & $p<0.01$ \\
\hline Fractional shortening $(\%)$ & $18.4 \pm 6.9$ & $3.5 \pm 5.8$ & $p<0.001$ \\
\hline Ejection time (msec) & $168.6 \pm 17.3$ & $163.1 \pm 18.2$ & NS \\
\hline Isovolumic contraction time (msec) & $54.6 \pm 7.3$ & $52.0 \pm 6.6$ & $p<0.05$ \\
\hline Isovolumic relaxation time (msec) & $72.1 \pm 26.4$ & $84.7+22.1$ & $p<0.05$ \\
\hline Systolic time index & $0.33 \pm 0.03$ & $0.32 \pm 0.03$ & NS \\
\hline Isovolumic index & $0.75 \pm 0.13$ & $0.84 \pm 0.13$ & $p<0.05$ \\
\hline
\end{tabular}

Values are mean \pm standard deviation.

$\mathrm{dP} / \mathrm{dt}=$ rate of change of pressure with time; NS = nonsignificant.

To further assess the impact of hemodynamic, functional, and time interval measurements on the isovolumic index, the value of each of these parameters was assessed at the point of the maximal isovolumic index value for each animal during ischemia. These data were averaged and compared to control by a paired $t$ test.

\section{RESULTS}

Hemodynamic consequences of the brief occlusion period included significant elevations of left ventricular end-diastolic pressure at 6 to 8 seconds $(p<0.01)$ and at 8 to 10 seconds $(p<0.001)$ (Table I). Peak negative $\mathrm{dP} / \mathrm{dt}$ was significantly depressed at 4 to 6 seconds $(p<0.01$ ), 6 to 8 seconds, and 8 to 10 seconds (each $p<0.001$ ). Heart rate, systolic blood pressure, and peak positive $\mathrm{dP} / \mathrm{dt}$ were not significantly affected by the brief coronary occlusion, and all hemodynamic variables returned to basal levels upon recovery.

Regional function was significantly altered throughout the occlusion period; the nadir was reached at 8 to 10 seconds, when fractional shortening fell to $1.9 \pm 7.3 \%$ from the control value of $18.4 \pm 6.9 \%(p<0.001)$. Time intervals showed disparate changes in response to brief myocardial ischemia. ET revealed no differences in any portion of the intervention. IVC time showed directional shortening that became significant $(p<0.01)$ by 8 to 10 seconds. IVR time showed a directional lengthening that became significant at 6 to 8 seconds $(p<0.01)$ and at 8 to 10 seconds $(p<0.05)$. The IVR half-time increased with the duration of ischemia, and was significantly elevated at 4 to 6 seconds $(p<0.05)$, at 6 to 8 seconds $(p<0.001)$, and at 8 to 10 seconds $(p<0.01)$. Each of these parameters returned to basal levels upon recovery.
The systolic time index was not significantly different from control at any point during the ischemic intervention. Directionally, this index showed a very slight shortening. Conversely, the isovolumic index, though also not significantly different from control, showed a directional increase that paralleled the functional deterioration revealed by fractional shortening.

The analysis of data at the point of the maximal deterioration of the isovolumic index is shown in Table II. Left ventricular end-diastolic pressure was significantly increased $(p<0.05)$ and peak negative $\mathrm{dP} / \mathrm{dt}$ was likewise decreased $(p<0.05)$. The fall in fractional shortening was highly significant $(p<0.001)$. The IVR half-time was significantly increased $(p<0.01)$, as was the IVR time $(p<0.05)$ (Fig. 1, A), while IVC time decreased ( $p<0.05$ ) (Fig. $1, B)$. ET showed a directional decrease in this analysis, but this was not significant (Fig. 1, C). Derivation of the isovolumic and systolic time indices from these data revealed a significant increase in the isovolumic index from control, but no change in the systolic time index (Fig. 2, $A$ and $B$ ).

\section{DISCUSSION}

This study assessed the comparative sensitivity of the isovolumic index and of the systolic time index during episodes of acute myocardial ischemia. A brief period of coronary occlusion resulted in prolongation of the IVR time, a decrease in IVC time, and no significant change in ET. These disparate responses, and particularly the preferential change in IVR time, polentiated the ability of the isovolumic index to discern the presence of ischemic myocardial dysfunction. In contrast, the traditional systolic 

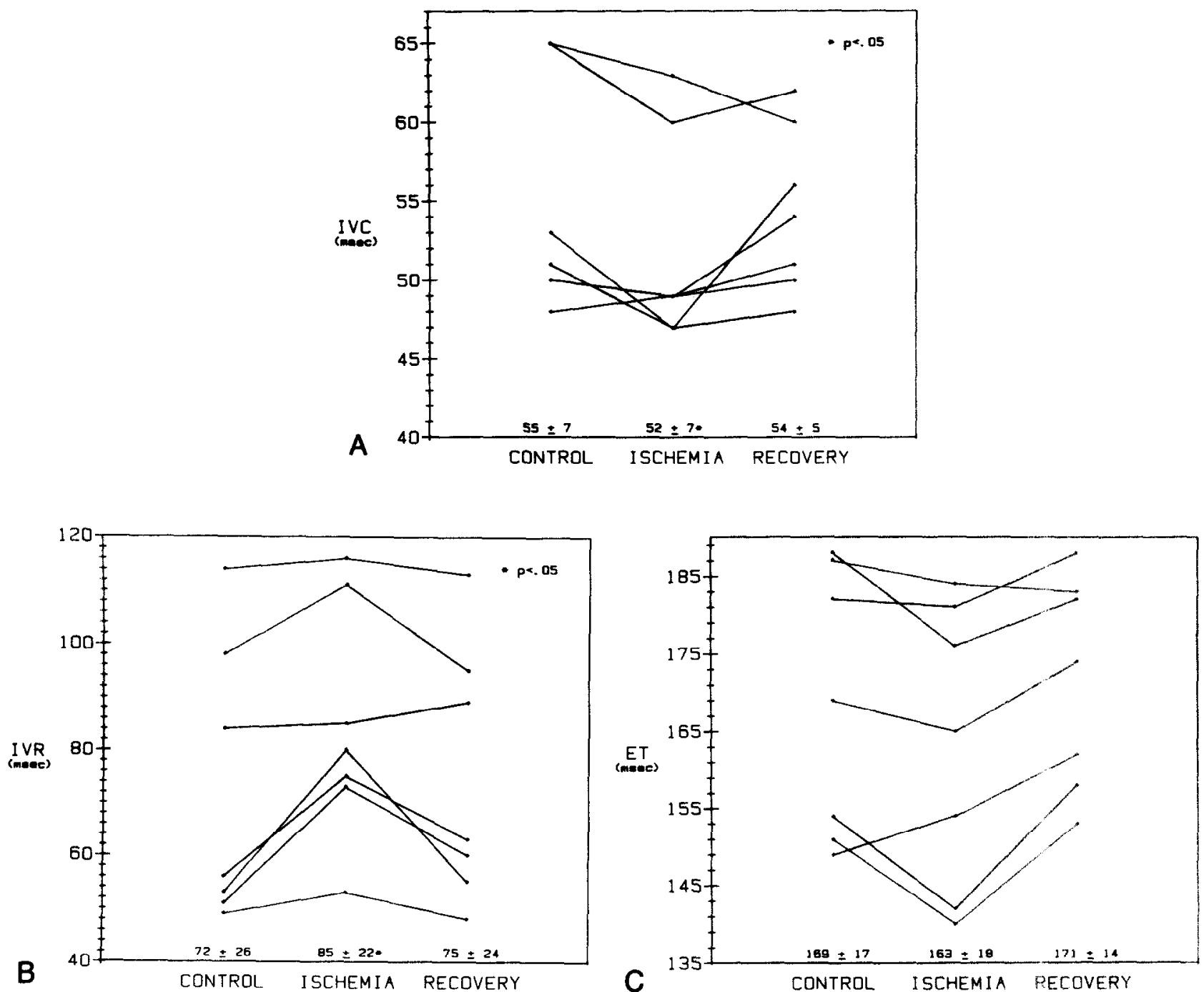

Fig. 1. Isovolumic contraction time, isovolumic relaxation time, and ejection time intervals, in milliseconds, assessed at the time of the maximal change in the isovolumic index. Data from each of seven dogs is represented graphically. Numerals $=$ mean \pm standard deviation. Panel $A$, Isovolumic contraction time was significantly shortened ( $p<0.05$ vs control) during ischemia. Panel $B$, Isovolumic relaxation time was significantly prolonged ( $p<0.05$ vs control) during ischemia. Panel $C$, Ejection time during ischemia was not significantly different from control. $I V C=$ isovolumic contraction time; $I V R=$ isovolumic relaxationtime; $E T=$ ejection time.

time index, defined as IVC time divided by ET, showed neither directional nor statistical change in response to ischemic dysfunction.

Ejection time. Changes in ET may be variable during ischemia. While prolongation of ET during acute ischemia can occur as a consequence of increased peripheral resistance ${ }^{23}$ and has been reported to occur postexercise in patients with angina pectoris, ${ }^{24}$ concomitant reductions in cardiac output and ejection fraction may offset this prolongation. ${ }^{25,}{ }^{26}$ The present study showed no significant changes in this interval during ischemia. A decrease in ET would have improved the ability of both the systolic time index and the isovolumic index to increase in response to ischemia. The somewhat greater effect of ET changes in the calculation of the systolic time index impaired the ability of this index to reflect ongoing dysfunction.

Isovolumic contraction time. As with measurements of ET, the response of IVC to acute ischemia is variable. Its duration is dependent upon left ventricular end-diastolic pressure, arterial diastolic pressure, and rate of change of pressure throughout the isovolumic period. ${ }^{27}$ Unfortunately, the response of this interval to these parameters is not consistently reproduced in the presence of ischemia: patients 

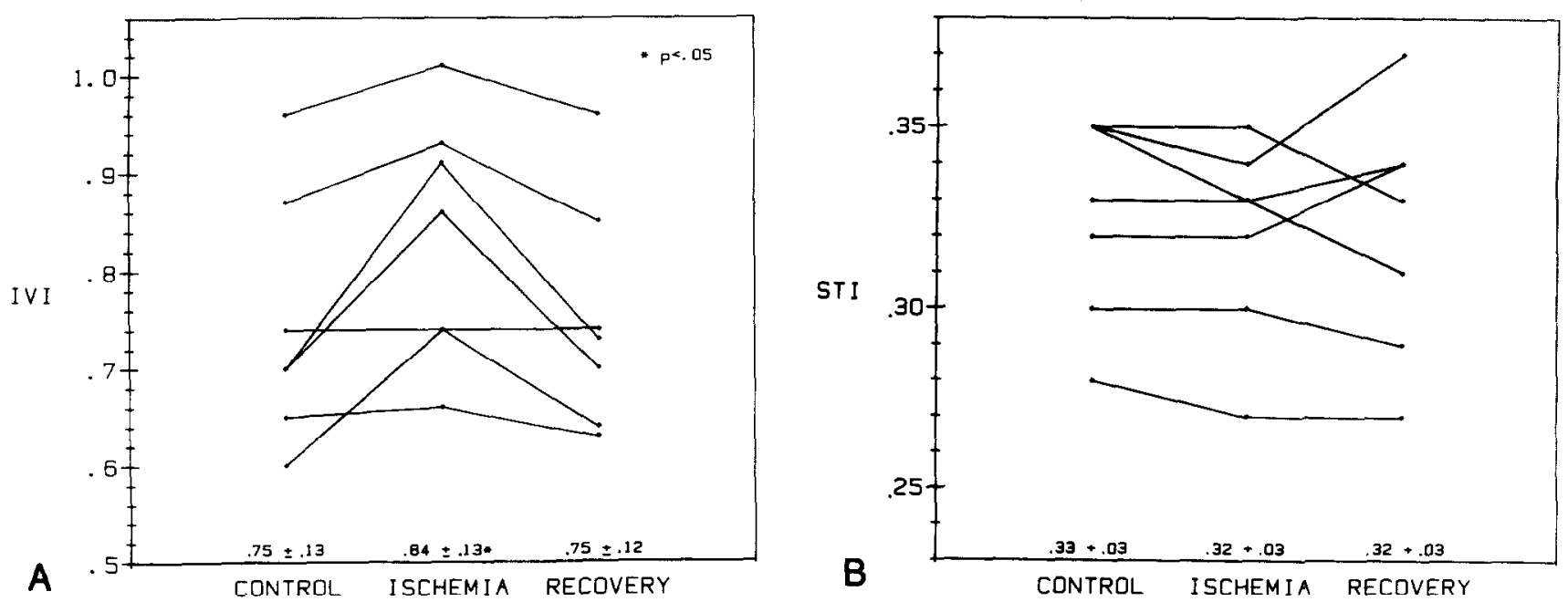

Fig. 2. Panel $A$, Maximal increase (deterioration) of the isovolumic index is significantly different from control $(p<0.05)$ during ischemia. Panel $B$, The systolic time index, assessed at the time of maximal change in isovolumic index, showed no significant change during ischemia. Data from each of seven dogs is represented graphically. Numerals $=$ mean \pm standard deviation; $I V I=$ isovolumic index; $S T I=$ systolic time index.

with induced angina have been reported to display either shortened IVC time ${ }^{25}$ or no change in this interval. ${ }^{26}$ Brief coronary occlusion in the present study resulted in directional shortening of IVC. This relatively mild response further hindered the ability of the systolic time index to reflect acute deterioration in myocardial function.

Isovolumic relaxation time. Myocardial relaxation has been shown to be a dynamic and energyrequiring phase of the cardiac cycle. ${ }^{28,29}$ Thus while modulated by the potential effects of left atrial pressure, aortic closing pressure, and rate of left ventricular pressure fall on IVR time, ${ }^{6,30,31}$ ischemia secondary to coronary occlusion is expected to prolong this interval. ${ }^{32}$ The present study did show lengthening of IVR that paralleled a prolonged IVR half-time and preferentially influenced the directional deterioration of the isovolumic index.

Assessment of time intervals at the time of maximal change of the isovolumic index further emphasized the effect of incorporating a measurement of myocardial relaxation (Table II). By this analysis, maximal deterioration of the isovolumic index was associated with significant depression of IVC time and significant prolongation of IVR. Importantly, even at this point of maximal change, the systolic time index failed to reveal deterioration of function.

The isovolumic index was developed to incorporate abnormalities of relaxation known to accompany myocardial dysfunction. The systolic time index, while useful in the diagnosis of chronic left ventric- ular disease, ${ }^{33,34}$ appears to be less sensitive when responses of ET and IVC time are mild or variable, as in brief ischemia. The nonsignificant and inconsistent response of the ET interval, and to a lesser extent the IVC time, appears to be a limitation, however, to implementation of even the isovolumic index in the noninvasive evaluation of acute ischemic episodes.

The authors would like to acknowledge the technical assistance of Kathleen Malik and John Hramiec.

\section{REFERENCES}

1. Grossman W, Barry WH. Diastolic pressure-volume relations in the diseased heart. Fed Proc 1980;39:148-55.

2. Lewis BS, Grotsman MS. Current concepts of left ventricular relaxation and compliance. AM HEART J 1980;99:101-12.

3. Hiroto Y. A clinical study of left ventricular relaxation. Circulation 1980;62:756-63.

4. Rousseau MF, Veriter C, Detry JMR, Brasseur L, Pouleur H. Impaired early left ventricular relaxation in coronary artery disease: effects of intracoronary nifedipine. Circulation 1980;62:764-72.

5. Benchimol A, Ellis JG. A study of the period of isovolumic relaxation in normal subjects and in patients with heart disease. Am J Cardiol 1967;19:196-206.

6. Lewis BS, Lewis N, Sapoznikov D, Gotsman MS. Isovolumic relaxation period in man. AM HEART J 1980;100:490-9.

7. Grossman W, McLaurin LP. Diastolic properties of the left ventricle. Ann Intern Med 1976;84:316-26.

8. Gibson DG, Prewitt TA, Brown DJ. Analysis of left ventricular wall movement during isovolumic relaxation and its relation to coronary artery disease. $\mathrm{Br}$ Heart J 1976;38:1010. 19.

9. D'Angelo R, Shah N, Rubler S. Diastolic time intervals in ischemic and hypertensive heart discase: a comparison of isovolumic relaxation time and rapid filling time with systolic time intervals. Chest 1975;68:56-61.

10. Mancini GBJ, Costello D, Bhargava V, Lew W, LeWinter M, 
Karliner JS. The isovolumic index: a new noninvasive approach to the assessment of left ventricular function in man. Am d Cardiol 1982;50:1401-7.

11. Mancini GBJ, Friedman HZ, Hramiec JE, DeBoe SF. The hemodynamic determinants of the isovolumic index. AM HEART J 1986;112:791-9.

12. Mancini GBJ, Malik K, Hramiec JE, Friedman HZ, DeBoe $\mathrm{SF}$. Pharmacologic alteration of the isovolumic index $[\mathrm{Ab}-$ stract]. Clin Res 1986;34:323A.

13. Abel Fl. Maximal negative $\mathrm{dP} / \mathrm{dt}$ as an indicator of end of systole. Am J Physiol 1981;240:H676-9.

14. Mahler F, Ross J Jr, O'Rourke RA, Covell JW. Effects of changes in preload, afterload and inotropic state on ejection and isovolumic phase measurements of contractility in the conscious dog. Am J Cardiol 1975;35:626-34.

15. Rubenstein JJ, Pohost GM, Dinsmore RE, Harthorne JW. The echocardiographic determination of mitral valve opening and closure: correlation and hemodynamic studies in man. Circulation 1975;51:98-103.

16. Tsakiris AG. Gordon DA, Padiyer R, Frechette D. Relation of mitral valve opening and closure to left atrial and ventricular pressures in the dog. Am J Physiol 1978;234:H146-51.

17. Laniado S, Yellin E, Kotler M, Levy L, Stadler J, Terdiman R. A study of the dynamic relations between the mitral valve echogram and phasic mitral flow. Circulation 1975;51:10413.

18. Pohost GM, Dinsmore RE, Rubenstein JJ, et al. The echocardiogram of the anterior leaflet of the mitral valve. Correlation with hemodynamic and cineroentgenographic studies in dogs. Circulation 1975;51:88-97.

19. Laniado S, Yellin EL, Miller H, Frater RWM. Temporal relation of the first heart sound to closure of the mitral valve. Circulation 1973;47:1006-14.

20. Katayama K, Kumada T, Fujii T, et al. Clinical characteristics of left ventricular pressure decline during isovolumic relaxation in normal and diseased hearts. AM HEART $J$ $1984 ; 107: 332-8$.

21. Mirsky I. Assessment of diastolic function: suggested methods and future considerations. Circulation 1984;69:836-41.

22. Neter J, Wasserman W. Applied linear statistical models. Homewood. Il]. Richard D. Irwin Inc,: 1974:382.
23. Shaver JA, Kroetz FW, Leonard JJ, Paley HW. The effect of steady state increases in systemic arteria pressure on the duration of left ventricular ejection time. . Clin Invest 1968;47:217-30.

24. Lewis RP, Marsh DG, Sherman JA, Forester WF, Schaal SF' Enhanced diagnostic power of exercise testing for myocardial ischemia by addition of postexercise left ventricular ejection time. Am J Cardiol 1977;39:767-74

25. Pouget JM, Harris WS, Mayron BR, Naughton JP. Abnormal responses of the systolic time intervals to exercise in patients with angina pectoris. Circulation 1971;43:289-98.

26. Ferro G, Piscione F, Carella G, Betocchi S, Spinelli I. Chiariello M. Systolic and diastolic time intervals during spontaneous angina. Clin Cardiol 1984;7:588-92.

27. Weissler AM, Schocnfeld CD. Effect of divitalis on systolic time intervals in heart failure. Am J Med Sci 1970;259:4-20.

28. Fanburg B, Finkel RM, Martonosi A. The role of calcium in the mechanism of relaxation of cardiac muscle. $f$ Biol Chem 1964;2298-2306.

29. Katz AM, Repke DI. Calcium-membrane interactions in the myocardium: effects of ouabain, epinephrine, and $3^{\prime}, 5^{\prime}$-cyclic adenosine monophosphate. Am J Cardiol 973;31:193-201.

30. Gamble WH, Shaver JH, Alvarez RF, Salerni R, Reddy PS. A critical appraisal of diastolic time intervals as a measure of relaxation in left ventricular hypertriphy. Circulation 1983;68:76-87.

31. Weisfeldt ML, Scully HE, Fredericksen .J. Hemodynamic determinants of maximum negative $\mathrm{dP} / \mathrm{al}$ t and periods of diastole. Am .J Physiol 1974;227:61:3-21.

32. Palacios I, Powell WJ Jr. Effect of acute Hobal ischemia on diastolic relaxation in canine hearts [Abstract] Am . Cardiol 1977;39:282.

33. Weissler AM, Harris WS, Schoenfeld CD. Systolic time intervals in heart failure in man. Circultion 1968;37:149. 59.

34. McDonald IG, Hobson ER. A comparison of the relative value of noninvasive techniques-echocardiography, systolic time intervals and apexcardiography--in the diagnosis of primary myocardial disease. AM HEART J 1974:88:454-62. 